\title{
Review \\ The Possibility of Assessing Pain with Biomarkers in Psychiatric Disorders
}

\author{
Piotr Jakubow 1,*, Urszula Kościuczuk 2, Adam Garkowski 3,

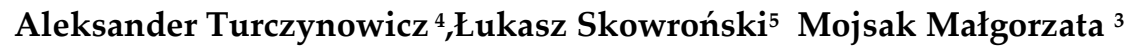 \\ Children and Adolescents Department of Anaesthesia and Intesive Care and Pain \\ Therapy Unit, Department of Palliative Medicine, Medical University of Białystok 15-215, \\ Poland. piotr.jakubow@umb.edu.pl * \\ 2 Department of Anaesthesiology and Intensive Therapy, Medical University of Bialystok 15- \\ 215; Poland urszula.kosciuczuk@umb.edu.pl \\ 3 Department of Radiology, Independent Department Laboratory of Molecular Imaging. Medical \\ University \\ of Białystok 15-215, Poland; adam.garkowski@gmail.com, malgorzata.mojsak@umb.edu.pl \\ 4 Medical University of Białystok 15-215, Poland; \\ aturczynowicz1@student.umb.edu.pl \\ 5 Medical University of Białystok 15-215, Poland; \\ skowronski.lukasz1989@gmail.com \\ *Correspondence: piotr.jakubow@umb.edu.pl; Tel.: +488-5746-8449
}

Abstract: According to the literature, patients with chronic pain and mental disorders constitute a huge, heterogeneous group. However, it is known that social and psychological processes closely affect the level and expression of chronic pain.

In this paper, we present a review of the literature, define methods of identifying pain biomarkers and consider the possibility of using them to assess pain in mental disorders. Group researchers searched PubMed, Scope, and Cochrane databases for "pain biomarkers in mental disorders" between 2011 and 2021. for available databases for full-text, peer-reviewed studies and review publications using the following keywords: pain biomarkers, neuroimaging pain, pain metabolomics, pain and psychiatric disorders, pain electroencephalography (EEG), serum pain biomarkers, saliva biomarkers, and diagnosis pain. The search included full-text articles, clinical trials, randomized controlled trials, and systematic reviews. Was used part of the PRISMA method to review the literature systematically. A literature search identified 283 studies based on the initially set inclusion and exclusion criteria. In the subsequent selection stages, 11 studies were selected for analysis. There are three main areas of the possible use of biomarkers for the clinical assessment of pain in psychiatric patients, neuroimaging, changes in metabolite levels in body fluids, and changes in gene expression. As a result of the review, individual pain mediators were distinguished that may be markers of pain in psychiatric patients. Some mediators indicate the specificity of pain and are of diagnostic importance. However, despite significant advances in research, most of the described biomarkers found in clinical trials assessing the severity and frequency of pain have no practical significance in psychiatric disorders. It is possible to diagnose pain based on neuroimaging using various methods, genetic methods, body fluids: blood and urine. Of the many, body fluid biomarkers are the most advanced. Discussion: Biomarker research is a dynamically developing field. The review has proposed new ways to diagnose pain by identifying pain biomarkers. Work presented pain diagnostics in psychiatric disorders based on biomarkers from various neuroimaging methods, blood and urine analysis. The possibility of new, effective techniques gives hope for the correct diagnosis of pain, especially in patients with mental 
disorders, which would allow for appropriate and adequate therapeutic therapies. In clinical practice is limited to a few methods. Assessment of pain biomarkers in body fluids (serum, saliva, and urine) seems to be the most practical and promising method of clinical application.

Conclusions: There are new techniques that give hope for the correct diagnosis of pain, especially in patients with mental disorders, which will allow for their proper and adequate therapy. According to the literature, patients with chronic pain and mental disorders constitute a huge, heterogeneous group. However, it is known that social and psychological processes closely affect the level and expression of chronic pain.

\section{Introduction}

Pain is one of many symptoms and major comorbidities of psychiatric patients, in-cluding those with psychosomatic and somatic disabilities [1,2]. According to epidemio-logical data, chronic pain affects up to $20 \%$ of the world's population and contributes sig-nificantly to the somatic impairment of patients with psychiatric disorders [3,4].

A working group of the International Association for the Study of Pain has developed a new classification of chronic pain for the International Classification of Diseases ICD-11 [5,6]. Chronic pain is defined as pain that persists or recurs for more than three months and may be conceived as a disease in its own right as "chronic primary pain" or related to other diseases as "chronic secondary pain" $[6,7]$. According to the literature, patients with chronic pain and psychiatric disorders are a huge heterogeneous group [7].

It has been reported that social and psychological processes impact the level and expression of chronic pain. In addition, there is evidence that chronic pain is associated with mental disorders and addiction to pain medications [8,9]. Patients with chronic pain and mental illness may suffer from affective disorders such as depression, personality impairment, dependence on analgesics, and various somatic disorders such as hypochondria [8,9]. There are also disorders that may be secondary to chronic pain, may precede the onset of pain, or may occur simultaneously, increasing the occurrence of both pain and mental impairment $[9,10]$. Recognition of pain is important as it influences treatment options and medication types [11]. Inadequate pain management methods can cause therapeutic complications and serious clinical problems, often including pain syndrome following incorrectly qualified invasive procedures and the lack of diagnosis of psychiatric disorders in somatic diseases. The most common problem is the excessive use of opioids, which has led to the opioid crisis in the US and Europe. Due to inadequate pain diagnosis, patients may have used strong painkillers such as opioids, although they should not be prescribed; therefore, in patients with substance use disorders (SUD) and other underlying psychiatric illnesses, proper pain diagnosis is essential.

Regardless of their etiological significance, any incorrect diagnosis may, as a result, increase pain and hinder recovery. [5].

The question arose whether it is possible to distinguish pain biomarkers in mental diseases so that its specific treatment can be applied in the future.

\section{Methods}

Following part of PRISMA guidelines, a structured electronic search of the literature was conducted in the PubMed, Scopus, and Cochrane databases figure 1. Eligible studies included the following criteria: (1) studies that analyzed pain assessment using biomarkers, (2) studies on pain assessment in patients with mental illnesses, (3) studies on assessment 
neuroimaging and biomarkers in body fluids, and (4) studies published in peer-reviewed journals from 2011 to 2021. (5) The articles included peerreviewed studies and review publications using the following keywords: pain biomarkers, pain neuroimaging, pain metabolomics, pain and psychiatric disorders, pain electroencephalography (EEG), serum pain biomarkers, saliva biomarkers, pain diagnosis, clinical pain assessment, mobile applications. Full-text articles, clinical studies, randomized controlled trials, and systematic reviews, were included in the search.

Articles on pain in children and adolescents, articles published without reviews, ar-ticles from popular science magazines, and editorials were excluded. No grey literature was included in the search and articles were independently reviewed for inclusion by two researchers who rated the quality of the articles.

Two researchers collected literature, and others checked the validity of the conclusions. The aim was to identify the necessary knowledge and practical diagnostic methods to determine specific pain biomarkers in mental disorders. To describe the specific features that are biomarkers of pain in psychiatric patients, it has been assumed that it is possible to apply determinations in the central nervous system, both through neuroimaging and other tests, as well as in body fluids, including cerebrospinal fluid, serum, urine, and saliva.

The Prisma analysis was not performed in full, the BIAS risk was not determined, and the obtained articles were described descriptively, not statistically. However, the entire material obtained was included in the analysis tab.1.

Table 1. The table shows studies included in qualitative synthesis.

\begin{tabular}{|l|l|}
\hline Reference studies included in synthesis \\
\hline $\begin{array}{l}\text { Review of neuroimaging studies related to pain modulation. Scand. } \\
\text { J. Pain 2011, 2, 108-120, doi:10.1016/j.sjpain.2011.05.005. }\end{array}$ & Knudsen, L.; \\
\hline $\begin{array}{l}\text { Cytokines in Neuropathic Pain and Associated Depression. Mod } \\
\text { Trends Pharmacopsychiatry. 2015;30:51-66.doi:10.1159/000435932. } \\
\text { PMID: 26437375. }\end{array}$ & Lees, JG, \\
\hline $\begin{array}{l}\text { The search for pain biomarkers in the human brain, Brain, } \\
\text { 2018;141,(12), 3290-3307, doi.org/10.1093/brain/awy281 }\end{array}$ & MourauX, A., \\
\hline $\begin{array}{l}\text { Brain Metabolite Changes in the Anterior Cingulate Cortex of } \\
\text { Chronic Low Back Pain Patients and Correlations Between } \\
\text { Metabolites and Psychological State. Clin J Pain. 2018,;34(7):657- } \\
\text { 663. doi: 10.1097/AJP.00000000000583. PMID: 29271797. }\end{array}$ & Kameda, T. \\
\hline $\begin{array}{l}\text { How do morphological alterations caused by chronic pain } \\
\text { distribute across the brain? A meta-analytic co-alteration study. } \\
\text { Neuroimage: Clin. 2018, 18, 15-30, doi:10.1016/j.nicl.2017.12.029. }\end{array}$ & \\
\hline
\end{tabular}




\begin{tabular}{|l|l|}
\hline $\begin{array}{l}\text { Towards precision medicine for pain: Diagnostic biomarkers and } \\
\text { repurposed drugs. Mol. Psychiatry 2019, 24, 501-522, } \\
\text { doi:10.1038/s41380-018-0345-5. }\end{array}$ & Niculescu, A.B.; \\
\hline $\begin{array}{l}\text { A neural circuit for comorbid depressive symptoms in chronic pain. } \\
\text { Nat Neurosci 2019; 22, 1649-1658, doi.org/10.1038/s41593-019- } \\
\text { 0468-2. }\end{array}$ & Zhou, W \\
\hline $\begin{array}{l}\text { Reduced Glutamate in the Medial Prefrontal Cortex Is Associated } \\
\text { With Emotional and Cognitive Dysregulation in People With } \\
\text { Chronic Pain. Front Neurol. 2019,3;10:1110. doi: }\end{array}$ & Naylor B, \\
10.3389/fneur.2019.01110. PMID: 31849800; & \\
\hline $\begin{array}{l}\text { Randomized Trial on the Clinical Utility of a Novel Biomarker Panel to Peabody, J. } \\
\text { Determinants of Chronic Pain. Diagnostics (Basel). 2020;10(8):513. Py } \\
\text { doi:10.3390/diagnostics10080513 }\end{array}$ & \\
\hline $\begin{array}{l}\text { Clinical Validation of a Multi-Biomarker Assay for the Evaluation of } \\
\text { Chronic Pain Patients in a Cross-Sectional, Observational Study. } \\
\text { Pain Ther. 2020,9(2):511-529.doi:10.1007/s40122-020-00175-3. }\end{array}$ & Amirdelfan, K. \\
\hline $\begin{array}{l}\text { Neuroinflammation, Pain and Depression: An Overview of the Main } \\
\text { Findings. Front Psychol. 2020,31;(11):1825. doi: } \\
\text { 10.3389/fpsyg.2020.01825. PMID: 32849076; PMCID: PMC7412934. }\end{array}$ & \\
\hline
\end{tabular}


Figure 1. PRISMA Flow Diagram for pain biomarkers in psychiatry 2011-2021
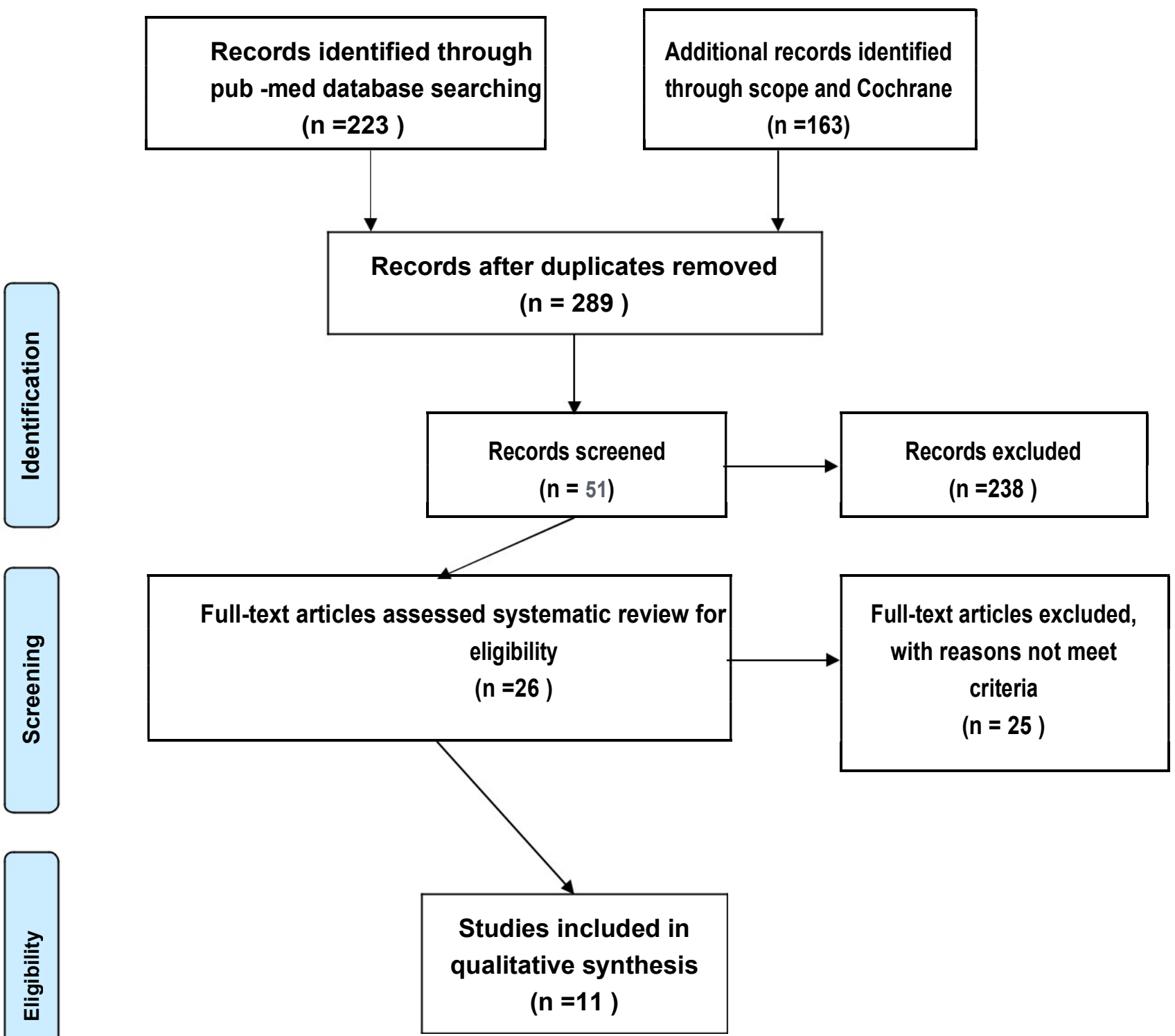

Figure 1. PRISMA diagram. The PRISMA method was used to systematically review the literature. We found 223 references in the pub med database, 160 publications in the scope, and 2 analyses in the Cochrane database matching the pain criteria searched by the presence of media-tors in psychiatry. After excluding redundant entries, 289 items remained, of which 238 did not meet the criteria. After the second analysis, 26 items were included in the study, from which 11 items were finally selected that fully describe the possibilities of using biomarkers in the assess-ment of pain. 
The diagnosis and differentiation of pain in practice is currently based on a patient's history and clinical symptoms, as well on pain assessment scales. There are many types of pain assessment widely used for detecting and quantifying pain.

Generally, batteries of pain tests are divided into two categories, i.e., visual analogy scales (VASs) in which patients indicate their pain level by marking the level on a scale, and numerical scales (NRSs) in which patients self-assess their pain using specific numbers that represent the level of pain experienced; usually, both categories are quantitative scales. The scales are both used to help improve communication between a physician and a patient during ther-apy and subsequent visits [11,12].

The most comprehensive assessments use certain adjectives as a tool to describe pain, and they can also use numbers, colors, body positions, and facial expressions to describe a certain type of pain. These are qualitative scales that may be used, in part, to determine the cause of the pain and the underlying health problems from which the pain arises [12,13]. Recent studies have demonstrated that software applications (mobile apps) that run on smartphones with traditional pain scales are useful for assessing pain. The use of mobile apps, which are accessible almost $24 / 7$, is particularly helpful in an outpatient set-ting. A mobileapplication-based intervention study demonstrated that pain apps can be useful for reducing pain among cancer and non-cancer pain patients [14-16].

In addition to our literature search, we searched for mobile applications that have been introduced for the identification of mental disorders, and which are considered to improve the contact and supervision of patients with both chronic pain and mental disor-ders [17,18] It's worth to mention that there are mobile applications introduced to identify mental disorders and considered as an improvement in contact and supervision with patients suffering not only from mental disorders per se, but also from chronic pain disorders as well. Those mobile apps however cannot be considered as biomarker, so they were not included in this review. There have also been studies on pain assessment based on facial expressions; algorithms use machine learning to automatically recognize physical expressions of pain. Despite advanced work, these assessment methods are not widely available; however, this technology is useful for evaluating children and patients who are unaware of their condi-tion $[19,20]$.

Individual pain assessment tools structured as scales are usually designed to assess a specific group of patients. There is a huge range of tools available for assessing neuro-pathic pain, including the Neuropathic Pain Questionnaire, Leeds Assessment of Neuro-pathic Symptoms, painDETECT questionnaire, Douleur Neuropathique 4 Questions (DN4), and many others. At the same time, specifically constructed tools such as the Fi-bromyalgia Survey Questionnaire, Comprehensive Regional Pain Syndrome Question-naire, Headache Questionnaire, and Migraine Disability Assessment Test [20] are used to classify individual pain units. This type of assessment tool is commonly used in practice. All of these behavioral scales are subjective, and one such test may not reflect the appro-priate intensity of pain, let alone the cause of the pain and the objective confirmation of its existence.

In addition, even the best subjective pain scales cannot confirm if the pain really ex-ists or is merely an image of the pain caused by consciousness. Another important factor in pain treatment is knowing to what extent the pain experienced by a patient is subjec-tively aggravated by their emotions. 
An important tool that combines the assessment of chronic pain and psychosocial state is the Multidimensional Pain Inventory (MPI), a questionnaire used to connect vari-ous categories of chronic pain to patients' psychosocial characteristics [21].

Concurrent with pain assessment studies, the intensity of emotions is assessed, but a diagnosis cannot easily be made based on a single visit and requires observation and long-term cooperation with a patient [22]. In parallel, identifying and treating any mental dis-orders or substance -use problems that may occur is essential for the successful rehabilita-tion of people with chronic pain [9].

In the case of chronic pain, the severity of pain is determined by the state of the human psyche, and therefore scales assessing the impact of emotions and cognitive functions on the perception of pain are used. Melzack developed the McGill Pain Questionnaire, and the following scales have been designed to more accurately assess the effects of factors other than nociception: Mental Pain Questionnaire (MPQ), Emory Pain Assessment Model, Minnesota Multiphase Personality Inventory (MMPI), Functional Assessment Screening Questionnaire (FASQ), Pain Disability Index (PDI), Pain Beliefs and Perceptions Inventory, etc. [22]. These types of pain assessment tool require the painstaking examina-tion of conversations and meetings with a patient, which do not completely eliminate the influence of various factors determining the duration of pain. Pain diagnosis is difficult and new tools for assessing pain are needed; therefore, it would be beneficial to identify unambiguous biomarkers of pain. Research to determine pain biomarkers in imaging and laboratory tests should be carried out and advanced $[23,24]$.

3.2. Possibilities of Assessing Serum, Urine and Saliva Pain Biomarkers.

Chronic pain coexists with some psychiatric disorders. Depression and anxiety can lead to chronic pain as well as its persistence [1].

The research made on schizophrenia patients in accordance to pain occurrence seem to be inconclusive. There have been different theories proposed as to pain factors in the disorder. In general it is assumed that pain in individuals with schizophrenia is not significantly different to healthy population. Some cases of analgesia prove rather mental factors and denial attitude to be determinant rather than biological disorder [76].

Some biological biomarkers in plasma such as interleukin-1, interleukin-6, interleukin-10, and tumour necrosis factor- $\alpha$ has been tested in connection with pain experience in psychiatric patients as well as healthy population for reference. It has been concluded that the level of interleukin-1 may be indicative for the occurrence and clinical symptoms of pain. Decreased concentration of interleukin10 may also be significant for prevalence and clinical appearance of mental disease related pain [77].

Release of pro-inflammatory molecules in microglial such as tumor necrosis factor- $\alpha$, interleukin $1 \beta$, interleukin 6 , inducible nitrous oxide synthase (iNOS), and reactive oxygen species influence both chronic pain and cognitive decline in Alzheimer's disease. Microglial pro-inflammatory activation in brain areas is interceding the affective component of pain and noesis [78].

Elderly patients have an increased risk of suffering from chronic pain. Patients with cognitive impairment particularly with dementia often have difficulties in identifying the level of pain they experience, because of the loss of verbal abilities to express pain. Non-invasive screening of inflammatory pain biomarkers such as 
salivary cortisol, salivary $\alpha$-amylase, secretory $\lg \mathrm{A}(\mathrm{s} \lg \mathrm{A})$, testosterone or tumour necrosis factor receptor type II (sTNF-RII) are prospective instruments for detecting the level of pain in elderly population. Apparently, slgA and sTNF-RII seem to be the most determining factors for pain identification in healthy population [79].

Complex regional pain syndrome (CRPS) is characterized by pain, autonomic re-sponses, hyperalgesia, and allodynia, and is associated with a proinflammatory state[64]. Different inflammatory profiles have been found in acute and chronic cases; in acute case CRPS, there are high levels of interleukin (IL)-8 and soluble tumor necrosis factor recep-tors, while in chronic phase CRPS, pain is associated with a broad representation of cyto-kines, NGF, substance $P$, and calcitonin generelated peptide (CGRP). The resulting pe-ripheral sensitization with vasodilation and extravasation of proteins explains the periph-eral symptoms and severity of clinical symptoms, including increases in interleukin-1, in-terleukin-6, and tumor necrosis factor $\alpha$ in tissues, blood, and CSF [64,65].

Pain in CRPS is considered to be caused by autoimmunity. The discoveries of self-targeting IgG and IgM analgesic antibodies in CRPS patients have confirmed this hypoth-esis. Blockading of the NK1 substance $P$ (SP) receptor using a selective LY303870 antago-nist has been observed to block CRPS-like nociceptive and vascular changes in CRPS mod-els [65].

Interestingly, many studies have demonstrated the important role of endogenous neurosteroids as pain biomarkers in psychiatric patients. Serum allopregnanolone levels are associated with the incidence of psychiatric disorders and chronic pain in military veterans [80]. Similarly, it has been observed that the occurrence of postmenopausal migraine in depressed women is also associated with low levels of allopregnanolone and normal levels of progesterone and testosterone [81]. In contrast, patients with bipolar disorder and a history of cannabis use had higher serum pregnanolone levels, lower al-lopregnanolone levels, higher pregnanolone to allopregnanolone ratio, and lower pregnenolone to pregnanolone ratio compared to those with no history of cannabis use. Similar results have not been seen in a history of other substance use disorders, except lower allopregnanolone levels in people with opioid use disorder [82]. Thus, the evaluation of neurosteroid levels as a pain biomarker in psychiatric patients requires further clarification [83].

Another pain disease associated with autoinflammation is cryopyrin-related autoin-flammatory syndrome, where the biomarker of pain is the NLRP3 gene, which is respon-sible for the protein cryopyrin that causes joint and muscle pain. Pain biomarkers in early sarcoidosis are the NOD2 gene and the NOD2 protein that cause joint and tendon pain, including intermittent fever associated with a TNF receptor such as the TNFRSF1A gene and the TNFR1 protein, which are responsible for pain in the muscles and joints, and for headaches [66,67].

A number of studies have evidenced that the primary nutritional, metabolic, and ox-idative stressors that cause the development or worsening of chronic pain are not recog-nized in clinics [69]. Other studies have shown that supplementing these deficiencies re-duces pain and improves the functioning of patients with mental problems [70]. Numerous studies have shown that there are strong associations between pain and depression, metabolic deficiencies, and oxidative stress, as well as biomarkers of stress metabolites [69,70,71]. Recently, there have been reports of advanced results in the determination of biomarkers of stress and pain in urine [72].

The Foundation Pain Index (FPI) is a new commercial test resulting from the algo-rithmic analysis of abnormal urinary metabolites correlated with clinical assessment of chronic pain [72]. FPI results group biomarker profiles in patients with chronic pain and correlate them with clinical symptoms and behavioral assessments of chronic pain [73]. 
Biomarkers in the FPI study can assess chronic inflammation mediated by cytokines (metabolites of the kynurenine pathway), biomarkers of oxidative stress (pyroglutamic acid, ethyl malonate and hydroxymethylglutarate), as well as micronutrient deficiencies (methylmalonic acid, xanthuric acid and homocysteine) and neurotransmitters (neuro-transmitters). 5) -hydroxy acids. All biomarkers are directly related to the development, worsening or increase in pain sensation [74].

Experimental studies have demonstrated significant clinical utility of an approved pain biomarker panel that identifies nutritional deficiencies, metabolic abnormalities, and oxidative stressors that lead to treatable causes of pain [72,75].

Table 2. The table shows serum, saliva and urine biomarkers identified in the review

\begin{tabular}{|c|c|c|}
\hline \multicolumn{2}{|c|}{ Functional biomarkers in serum, urine and saliva } & \multirow{10}{*}{$\begin{array}{l}\text { Reference } \\
\text { Gunn, } 2020\end{array}$} \\
\hline Quinolinic acid & $\begin{array}{l}\text { Elevated in } 29 \% \text { of patients, } \\
\text { indicates chronic inflammation } \\
\text { mediated by pro-inflammatory } \\
\text { cytokines, metabolite of the } \\
\text { kynurenic pathway }\end{array}$ & \\
\hline Kynurenic acid & $\begin{array}{l}\text { Elevated in } 27 \% \text { of patients, } \\
\text { indicates chronic inflammation } \\
\text { mediated by pro-inflammatory } \\
\text { cytokines, metabolite of the } \\
\text { kynurenic pathway, supportive } \\
\text { marker of chronic pain }\end{array}$ & \\
\hline $\begin{array}{l}\text { 3-hydroxypropyl } \\
\text { mercapturic acid }\end{array}$ & $\begin{array}{l}\text { Elevated in } 21 \% \text { of patients, indicator } \\
\text { of acrolein exposure to nerve health }\end{array}$ & \\
\hline Pyroglutamic acid & $\begin{array}{l}\text { Elevated in } 19 \% \text { of patients, indicator } \\
\text { of glutathione and oxidative stress }\end{array}$ & \\
\hline Xanthurenic acid & $\begin{array}{l}\text { Elevated in } 17 \% \text { of patients, marker } \\
\text { of vitamin B6 insufficiency }\end{array}$ & \\
\hline Homocysteine & $\begin{array}{l}\text { Elevated in } 11 \% \text { of patients, } \\
\text { indicator of vitamin B6/B9 or B12 } \\
\text { deficiency and nerve health }\end{array}$ & \\
\hline Hydroxymethylglutarate & $\begin{array}{l}\text { Elevated in } 11 \% \text { of patients, } \\
\text { Coenzyme } Q 10 \text { deficiency and } \\
\text { oxidative stress }\end{array}$ & \\
\hline Methylmalonic acid & $\begin{array}{l}\text { Elevated in } 10 \% \text { of patients, } \\
\text { indicates low levels of vitamin } \\
\text { B12 and nerve health }\end{array}$ & \\
\hline Ethylmalonic acid & $\begin{array}{l}\text { Increased in } 10 \% \text { of patients, } \\
\text { marker of carnitine/vitamin } \\
\text { B2 insufficiency, suggests } \\
\text { oxidative stress }\end{array}$ & \\
\hline Interleukin 8 & (I) in acute phase of CRPS ${ }^{[64,65]}$ & $\begin{array}{l}\text { Marinus, } 2011[64] ; \\
\text { Clark, } 2018 \text { [65] }\end{array}$ \\
\hline
\end{tabular}




\begin{tabular}{|c|c|c|}
\hline $\begin{array}{l}\text { Soluble tumor necrosis } \\
\text { factor } \quad \text { receptors } \\
\text { (sTNFRs) }\end{array}$ & $\begin{array}{l}\text { (I) in acute phase of } \mathrm{CRPS}^{[64,65]} ;(\mathrm{I}) \\
\text { levels in sarcoidosis-related } \\
\text { musculoskeletal pain, } \\
\text { headaches }^{[66,67]}\end{array}$ & $\begin{array}{l}\text { Marinus, } 2011 \text { [64]; } \\
\text { Clark, } 2018[65] ; \\
\text { Kong, } 2013[66] ; \\
\text { Backryd, } 2015[67]\end{array}$ \\
\hline $\begin{array}{l}\text { NGF (nerve growth } \\
\text { factor) }\end{array}$ & \multirow[t]{4}{*}{$\begin{array}{l}\text { (I) levels in chronic phase of } \\
\text { CRPS }^{[64,65]}\end{array}$} & \multirow[t]{4}{*}{$\begin{array}{l}\text { Marinus, } 2011[64] \\
\text { Clark, } 2018[65]\end{array}$} \\
\hline Substance $\mathrm{P}$ & & \\
\hline $\begin{array}{l}\text { CGRP (calcitonin gene } \\
\text { related peptide) }\end{array}$ & & \\
\hline $\begin{array}{l}\text { Inflammatory cytokines } \\
\text { spectrum }\end{array}$ & & \\
\hline $\begin{array}{l}\text { NLRP3 gene and } \\
\text { cryopyrin }\end{array}$ & $\begin{array}{l}\text { (I) in cryopyrin-related } \\
\text { autoinflammatory disease, } \\
\text { cryopyrin causes joint and muscle } \\
\text { pain }^{[66,67]}\end{array}$ & \multirow[t]{2}{*}{$\begin{array}{l}\text { Kong, } 2013 \text { [66]; } \\
\text { Backryd, } 2015 \text { [67] }\end{array}$} \\
\hline $\begin{array}{l}\text { NOD2 gene and NOD2 } \\
\text { protein }\end{array}$ & $\begin{array}{l}\text { (I) in joint and tendon pain in } \\
\text { sarcoidosis } \\
\end{array}$ & \\
\hline
\end{tabular}

\subsubsection{Biomarker Gene Expression}

An important study of pain biomarkers was an advanced research model conducted on psychiatric patients at high risk of comorbid pain disorders and increased pain perception [68]. The expression of putative pain biomarker genes was shown to correlate with pain symptoms; this association was shown for $\mathbf{G}$ gamma 7 protein subunit (GNG7), con-tactin 1 (CNTN1), lymphocyte antigen 9 (LY9), helix 144b (CCDC 144b), and guanylate binding protein 1 (GBP1), among others [71]. This study found that GNG7 was a strong predictor of future painrelated emergency room visits, while CNTN1 was a strong pre-dictor of pain intensity. In addition, a new biomarker characterized by the expression of the MFAP3 gene was identified, which, in the literature, had no previous evidence of in-volvement with pain [67]. Pain biomarkers have been shown to vary based on gender and diagnosis. CNTN1 is associated with chronic pain in women, while LY9 (lymphocyte an-tigen 9) and MFAP3 are associated with pain caused by posttraumatic stress disorder (PTSD) in men.

In addition, the gene expression signature can be used to assess the response to tested drugs, such as SC-560 (NSAID) and amoxapine (an antidepressant), as well as to natural compounds such as pyridoxine (vitamin B6), cyanocobalamin (vitamin B12), and apigenin (a plant flavonoid) [68]. 
Table 3. The table shows promising gene expression pain biomarkers identified in the review.

\begin{tabular}{|c|c|c|}
\hline \multicolumn{2}{|c|}{ Biomarkers gene expression } & Reference \\
\hline $\begin{array}{l}\text { GNG7 (G Protein } \\
\text { Subunit Gamma 7) }\end{array}$ & $\begin{array}{l}\text { (D) in high pain states (HPS), strong } \\
\text { predictor of all future pain-related ED } \\
\text { visits, involved in chronic pain states } \\
\text { (diabetic neuropathy, vertebral disc } \\
\text { herniation), high trans-diagnostic } \\
\text { evidence of involvement in } \\
\text { alcoholism, stress, and hallucinogens } \\
\text { abuse }^{[68]}\end{array}$ & Niculescu, 2019 [68] \\
\hline CNTN1 (Contactin-1) & $\begin{array}{l}\text { (D) in chronic pain states such as } \\
\text { chronic widespread pain in women, } \\
\text { chronic inflammatory demyelinating } \\
\text { polineuropathy, trans-diagnostic } \\
\text { evidence of involvement in } \\
\text { psychiatric disorders in females. }{ }^{[68]}\end{array}$ & Niculescu, 2019 [68] \\
\hline $\begin{array}{l}\text { LY9 (lymphocyte } \\
\text { antigen 9) }\end{array}$ & $\begin{array}{l}\text { (I) in HPS, good predictor for state } \\
\text { and trait, especially for males with } \\
\text { PTSD }{ }^{[68]}\end{array}$ & Niculescu, 2019 [68] \\
\hline $\begin{array}{l}\text { GBP1 (guanylate } \\
\text { binding protein } 1 \text { ) }\end{array}$ & $\begin{array}{l}\text { (I) in expression in HPS, predictor for } \\
\text { trait in females, (I) in expression in the } \\
\text { brain in MDD, schizophrenia and } \\
\text { suicidality, and in blood in PTSD } \\
\text { patients }^{[68]}\end{array}$ & Niculescu, 2019 [68] \\
\hline $\begin{array}{l}\text { MFAP3 (microfibril } \\
\text { associated protein 3) }\end{array}$ & $\begin{array}{l}\text { (D) in HPS, strong predictor of pain } \\
\text { intensity in males and females with } \\
\text { PTSD, a novel pain-related gene } \\
\text { expression biomarker with no } \\
\text { previous evidence in literature }{ }^{[67]}\end{array}$ & $\begin{array}{l}\text { Backryd, 10`5 [67]; } \\
\text { Niculescu, } 2019 \text { [68] }\end{array}$ \\
\hline
\end{tabular}

\subsubsection{Looking for Pain mediators in the Brain}

Recently, studies have proposed new approaches for pain diagnostics using various neuroimaging techniques. These techniques include electroencephalography (EEG), magnetoencephalography (MEG), multiple magnetic resonance imaging (MRI), functional magnetic resonance imaging (fMRI), positron emission tomography (PET), and functional near- infrared spectroscopy (fNIRS), and are aimed at identifying images of markers of pain, namely biomarkers of pain in the brain that can represent structural, functional, and neurochemical changes [25,26].

The anatomical domain of this imaging (e.g., MRI/PET) represents changes in the volume of a part of the brain area involved in chronic pain. The functional domain of imaging (e.g., fMRI) shows the altered dynamic state of the brain in chronic and acute pain, and the chemical domain of imaging (e.g., magnetic resonance spectroscopy, MRS) measures chemical changes in the brain. Studies have shown that, performed together, these three domains make it possible to assess and interpret the presence of chronic pain [27,28].

All of the abovementioned techniques provide noninvasive methods of studying nervous structures in humans. Studies have shown that fMRI provides better temporal and spatial resolution than PET, and nowadays, this method is 
more commonly used to measure indirect pain. Nevertheless, it has also been widely reported that pain-related brain activation observed using these functional techniques corresponds to advanced anatomical studies that indicate existing nociceptive connections in the brain [29].

Other studies have developed fMRI patterns that can predict the intensity of a pa-tient's pain using machine learning analysis. Pattern activity has been demonstrated in areas of the brain that are associated with damaging stimuli pain and include all structures associated with pain stimulus processing, such as the thalamus, anterior and posterior insula, somatosensory cortex, and anterior cingulate cortex $[29,30]$.

Some studies have demonstrated the ability to predict pain from fMRI changes to distinguish painful heat from nonpainful heat. These fNMR studies have also found that there is a difference between physical and social pain and that all fMRI changes are sup-pressed after opioid administration [30,31].

An analysis of the literature reviews on fMRI studies of chronic pain patients indi-cated that an increase in pain can be predicted by signals in the brain's reward system. The onset of chronic pain involves reorganization of the entire brain network, including at rest. Additionally, fMRI can predict a fixed pain sensation by observing the functional connections of the left fronto-parietal network [32,33].

A new and interesting technology simultaneously measures neural responses to nox-ious stimuli in the central nervous system. Simultaneous corticospinal imaging of brain- spinal interactions demonstrates the role of functional connectivity throughout the brain area in the formation of pain [34].

An alteration in gray matter volume remodeling in patients with a prognosis of chronic pain has also been demonstrated based on voxel morphometric changes in back pain and abnormalities in white matter and brain connectivity [10,34].

Another interesting phenomenon is when anatomical changes reverse after pain re-lief, and therefore, as have reported, anatomical changes may be associated

hyperalgesia was associated with a reduction in the volume of the bilateral area of the hindlimb, the anterior cingulate cortex, and islets [35,36].

Proton magnetic resonance spectroscopy (1H-MRS) in patients with fibromyalgia has shown increased levels of the excitatory neurotransmitter glutamate and decreased levels of GABA (gamma-Aminobutyric acid), inhibitory neurotransmitters in the posterior re-gion insula as compared with healthy subjects [34,37]. This suggests that the posterior part of the insula is a painpromoting area whose hyperactivity influences of the pain syn-drome [38]. A rat model of neuropathic pain has been shown to generate analogous changes, where increasing glutamate and decreasing GABA levels in the insula resulted in mechanical allodynia $[39,40]$. Gabapentinoids such as pregabalin have been reported to reduce abnormal glutamate signals in patients with fibromyalgia [41].

According to the literature, the areas of the brain involved in pain processing are the primary and secondary somatosensory cortex, insular cortex (IC), anterior cingulate cor-tex (ACC), prefrontal cortex (PFC), thalamus, and cerebellum [10].

The regions for processing emotions, memory, and fear in the amygdala, hippocam-pus, and subcortical structures, including the basal ganglia, are the most frequently acti-vated regions in association with pain signals $[40,41]$.

Acupuncture pain studies have shown that the gray periapical area (PAG) is one area that is activated by most pain mechanisms. Interestingly, various ventromedial atrial ac-tivity known to carry descending PAG modulation was observed during both acupunc-ture anesthesia and anxiety-induced hyperalgesia. Other areas of the brain that appear to be involved in pain mechanisms, such as the anterior cingulate cortex, prefrontal cortex, orbitofrontal cortex, and nucleus accumbens were not activated simultaneously in these patients $[42,43]$. 
Due to the increase in pain complaints and significant impairment of functioning, many studies have been conducted on quick diagnostic methods by determining pain bi-omarkers in complex regional pain syndrome (CRPS) [43].

In adults and children, complex regional pain syndrome (CRPS) develops in parts of the body after an injury, stroke, sprain, or fracture. There are often pathological changes in bone and skin, as well as extreme sensitivity to touch, known as allodynia. The condi-tion is thought to be a malfunctioning of the peripheral and central antinociceptive sys-tem. Early correct diagnosis is thought to be important for preventing progression, and therefore avoiding a long-lasting disability [44].

In patients with CRPS, CNS fMRI imaging showed an association of pain with acti-vation of connections between the middle prefrontal cortex (MPFC), cingulate gyrus, and the lower parietal lobe. Increased connectivity of MPFCs with insular cortex has also been demonstrated with increasing symptoms.

Resting fMRI showed gray matter atrophy in the right islet, right ventromedial pre-frontal cortex (VMPFC), and right nucleus accumbens in CRPS patients [44]. Similarly, 18F-FDG-PET (Positron Emission Tomography with fluorodeoxyglucose $F$ 18) has been used to show increased glucose metabolism in many pain-related brain regions; magneto-encephalographic (MEG) studies at rest have demonstrated abnormal electrophysiology in the orbitofrontal-temporal cortices and somatosensory cortex, which, respectively, hint at deficits in affective pain perception and pain localization in CRPS patients [44].

According to the literature on proton magnetic resonance spectroscopy $(1 \mathrm{H}$ MRS), depleted levels of $\mathrm{N}$-acetylaspartate (a marker of neuronal density) and other identifiable chemicals relative to creatine in four bilateral brain regions (the dorsolateral prefrontal cortex, orbitofrontal cortex, cingulate, and thalamus) can be a marker for CRPS syndrome [45].

Another fMRI study found functional abnormalities in the thalamus and primary so-matosensory cortex (S1) of the brain. As expected, CRPS patients showed poor acuity of painful limb touch related to the strength of functional thalamo-S1 connectivity. CRPS subjects displayed stronger thalamo-S1 functional connectivity than controls, and this was related to the intensity of the pain [46].

With a magnetic field scan performed by standard MR sequences (T1-weighted and T2-weighted images, 3D FLAIR, DWI, and ADC sequences) and 1H-MRS, it is possible to assess metabolites by microglial activation. $\mathbf{N}$-acetylaspartate (NAA, a marker of neuron density), choline (Cho, an indicator of myelin breakdown products, building the sheaths of nerve cells), and myo-inositol ( $\mathrm{ml}$ ) are considered to be markers of microglial activa-tion. Using the single voxel spectroscopy (SVS) method, it has been possible to assess the differences between both hemispheres of the brain in CRPS patients at the following loca-tions: insula, thalamus, basal ganglia, and postcentral gyrus [11-14,46]

Single voxel $1 \mathrm{H}-\mathrm{MRS}$ is a noninvasive method for in vivo quantification of several different brain metabolites including $\mathrm{N}$-acetylaspartate (NAA, a marker of neuronal den-sity), choline-containing compounds (Cho, an indicator of myelin breakdown products, building the sheaths of nerve cells), creatine ( $\mathrm{Cr}$, energy metabolism marker), myo-inositol ( $\mathrm{ml}$, a marker of microglia activation) and glutamate- glutamine (GIx, excitatory neuro-transmitter and precursor amino acid). The advantage of this method is that it may pro-vide information about metabolite alterations in the brain, while MRI fails to reveal any morphological abnormalities. The 1H-MRS study showed changes in the presence of me-tabolites in patients with CRPS. The spectrum from basal ganglia on the diseased side of $1 \mathrm{H}-\mathrm{MRS}$ showed 
a marked increase in choline (Cho) and a relative decrease in $\mathrm{N}$-acetyl aspartate (NAA) compared to the spectral levels of creatine [47].

A reduced level of $\mathrm{N}$-acetylaspartate in the bilateral dorsolateral prefrontal cortex and an increased level of myo-inositol (a marker of activated microglia) in the left orbito-frontal cortex of a patient with intractable severe pain were found also in another CRPS study [48].

Machine learning techniques are increasingly used in functional imaging studies, in-cluding for pain recognition. Examination used EEG analysis to assess the potential anal-gesic response to morphine administration. Machine learning based on electroenceph-alography, applied to patients in the pain-free period before treatment, has enabled an algorithm to separate responders from nonresponders $[49,50]$.

Structural and functional magnetic resonance imaging analyzed by multivariate pat-tern analysis (MVPA) can accurately distinguish between people with Musculoskeletal Pain and healthy people [51]. The main network identified by the MVPA is the neurolog-ical pain signature (NPS) [10,52,53], which is sensitive and specific to pain in individuals and involves brain regions that receive afferents nociceptive information [54]. The NPS is promisingly accurate for noxious stimuli but does not correctly capture all effects, i.e., the effects of cognitive regulation and the effects of perceived control on pain [54].

A new tool [54] evaluates the multivariate fMRI signature, termed stimulus intensity independent pain signature-1 (SIIPS1), and can predict changes in pain above and beyond the noxious stimulus intensity and the nociceptive brain processes estimated by NPS [53- 55].

This interesting study shows that both social information and individual learning independently influence the perception of pain [54]. The brain regions involved in pain modification are very different. The limbic and posterior regions of the brain mediate con-ditioning effects, while the prefrontal and parietal regions more strongly mediate the im-pact of social information on pain. Taken together, these results suggest that top -down modulation of experience may come from diffuse sources in the frontoparietal and limbic regions, depending on the source of information [52, 54]. Expectations caused by social influence and instructions can be especially powerful in shaping perceptions and experi-ences by bypassing learning networks and directly engaging in fused higher-level pre-frontal and parietal areas. Taken together, these results suggest that top-down modulation of experience may come from diffuse sources in the frontoparietal and limbic regions, de-pending on the sources of information [54]. These works showed that the psychological effect of pain is very complex and, at the same time, dispersed in the structures of the CNS.

Although no clear central representation has been identified, pain treatment can be observed by signature like as biomerkers. A double-blind, randomized, placebo-con-trolled, three-way crossover study with fMRI in a sensitization model in a healthy volun-teer generated a signature database and correctly differentiated between decreased gabapentin and brain pain response [55]. However, in real life, excessive consumption of gabapentinoids has been observed despite a good analgesic effect [55]. Moreover, emo-tional pain is just as important to the patient and should not be considered to be "second-class" pain, although it is difficult to understand and diagnose. Machine learning methods that generate emotional pain signatures/biomarkers that have their own specificity and sensitivity would be diagnostically helpful in this regard [54-55]. Unfortunately, such a procedure is not universal, and a complete clinical evaluation is still required in the as-sessment of chronic pain [10]. 
One method of neuroimaging is functional near infrared spectroscopy (fNIRS) [56]. It is a noninvasive technology that indicates brain activity in areas underneath sensors and can measure the activity of the cerebral cortex in response to painful stimulation. The advantage of fNIRS is that it can be used in real clinical conditions, where it is mainly used to assess the metabolism of the frontal lobes by reading oxygenation of the brain tissue and blood flow hemodynamics. Due to its noninvasiveness, fNIRS is used in a variety of clinical settings, including operating theaters, patient rooms, and experimental settings. The use of fNIRS has been demonstrated to assess pain in response to various types of thermal stimulation with high measurement accuracy [56].

\subsubsection{Emotions Alter Nociceptive Responsiveness}

Neuroimaging biomarkers can be used to assess the influence of emotions on the de-velopment of pain. An fNMR study showed that a subject's observation of frightened fa-cial expressions caused discomfort and anxiety with simultaneous activation of pain neu-rons in the ACC $[10,57,58]$.

Several studies have shown a parallel effect of the state of attention and mood on the perception of pain. In one study, subjects were allowed to alternate between a painful stimulus and a smell presented at the same time; by manipulating mood and attention, a activation of pain neurons in the ACC was demonstrated [59,60.61].

Increased neuronal activity in the ACC and the accompanying activation of other individual pain areas in the brain have also been demonstrated as a result of changes in a patient's mood under the influence of reading and listening to sad comments and music. It has been observed that changes in negative emotions caused by auditory stimuli result in increased activity of pain areas in the frontal lobe as well as the ACC and hippocampus [10,62,63,64].

The activity of pain- related neurons of the brain, such as the brain's limbic system, ACC, frontal cortex, and hippocampus, is a biomarker for both pain and the emotional changes that cause pain. Pharmacological modulation of the nerve pathways involved in emotional transmission modulates the perception of pain, and the condition can also be monitored using neuroimaging. For example, in neuroimaging, opiate -sensitive pathways from the frontal cortex to the amygdala, PAG, ventral spinal cord (RVM), and dorsal atrium have been shown to be involved in the attention-dependent modulation of pain $[25,65,66]$.

Using functional connectivity analysis, it has been shown [66] that the frontoPAG circuits are associated with the emotional component of pain, and changes in the upper parietal lobe, which is part of the attention orientation system, can be modulated by pain. In the same work, using fNRM neuroimaging, descending pathways of pain modulation were distinguished, which are responsible for the psychological modulation of pain $[51,56]$.

The nerve pathways involved in pain, from the ACC to the PFC, and then to the PAG, and the island pathway through the amygdala body to the PAG have been identified as less prone to modulation and alteration of the pain signal than the ascending pathways [28]. 
Table 4. This table shows possible pain biomarkers that can be found in neuroimaging.

\begin{tabular}{|c|c|c|}
\hline \multicolumn{2}{|c|}{ Biomarkers in neuroimaging } & Reference \\
\hline \multirow[t]{2}{*}{$\begin{array}{l}\text { 1H-MRS of the brain } \\
\text { (proton magnetic } \\
\text { resonance } \\
\text { spectroscopy }\end{array}$} & 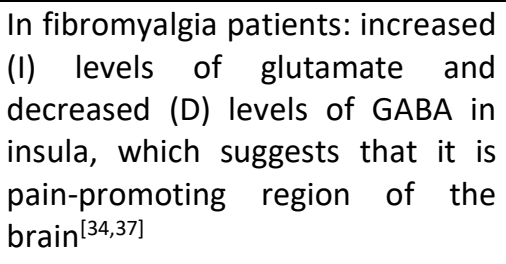 & $\begin{array}{l}\text { Tatu, } 2018 \text { [34]; } \\
\text { Davis, } 2017 \text { [37] }\end{array}$ \\
\hline & $\begin{array}{l}\text { In CRPS (complex regional pain } \\
\text { syndrome): in basal ganglia on the } \\
\text { diseased side - (I) choline, (D) } \\
\text { NAA }^{[45,47] ; ~(D) ~ N A A ~ i n ~ b i l a t e r a l ~} \\
\text { dorsolateral prefrontal cortex, (I) } \\
\text { level of myo-inositol in left } \\
\text { orbitofrontal cortex }\end{array}$ & $\begin{array}{l}\text { Walton, } 2010[45] ; \\
\text { Jakubów, } 2020[47] ; \\
\text { Gram, } 2015[48]\end{array}$ \\
\hline \multirow[t]{3}{*}{$\begin{array}{l}\text { fMRI (functional } \\
\text { magnetic resonance) }\end{array}$} & $\begin{array}{l}\text { In mechanical hyperalgesia: } \\
\text { reduction of volume of the } \\
\text { bilateral hindlimb area, anterior } \\
\text { cingulate cortex, islets }^{[35,36]}\end{array}$ & $\begin{array}{l}\text { Jung, } 2019 \text { [35]; } \\
\text { Seminowicz, 2009 [36] }\end{array}$ \\
\hline & $\begin{array}{l}\text { Gray peripheral area (PAG) is } \\
\text { activated by most pain } \\
\text { mechanisms }\end{array}$ & $\begin{array}{l}\text { Knudsen, } 2011 \text { [42]; } \\
\text { Maihoefner, } 2004 \text { [43] }\end{array}$ \\
\hline & $\begin{array}{l}\text { In CRPS: pain is associated with (I) } \\
\text { connectivity between MPFC, } \\
\text { cingulate gyrus, lower parietal } \\
\text { lobe, (I) connectivity between } \\
\text { MPFC and insular cortex; (I) activity } \\
\text { in connection between thalamus } \\
\text { and primary somatosensory } \\
\text { cortex }{ }^{[46]} \text {; gray matter atrophy in } \\
\text { right islet, right VMPFC, right } \\
\text { nucleus accumbens }{ }^{[44]}\end{array}$ & $\begin{array}{l}\text { Jung, } 2018 \text { [44]; } \\
\text { Di Pietro, } 2020 \text { [46] }\end{array}$ \\
\hline $\begin{array}{lr}\text { fNIRS } & \text { (functional } \\
\text { near } & \text { infrared } \\
\text { spectroscopy) }\end{array}$ & $\begin{array}{l}\text { (I) metabolism of frontal lobes } \\
\text { measured by oxygenation and } \\
\text { blood flow, fNIRS measurement } \\
\text { shown good accuracy in assessing } \\
\text { pain in response to thermal } \\
\text { nociceptive stimulation }{ }^{[56]}\end{array}$ & Rojas, 2019 [56] \\
\hline
\end{tabular}

\section{4.. Conclusions}

Pain is a complex experience, which includes somatic, affective, cognitive, and behavioural features, all of which are the result of mental processes, and therefore represents a psychological condition. Chronic pain is very difficult to evaluate, and even harder to heal, because the memory of it and accompanying emotions last for many years. There-fore, many diagnostic and therapeutic schemas, biomarkers, and algorithms have been introduced to adequately control pain. Patients with mental disorders and diseases who do not exhibit patterns in the diagnosis and therapy processes present a problem. There-fore, the treatment of chronic pain should be a comprehensive procedure, in which specialists from various fields of medicine, including psychologists, psychiatrists, social workers, 
and educators, are involved in the process of diagnosis and therapy. Such a comprehensive therapy gives hope for proper and

effective pain treatment. Information regarding the developed and standardized pain biomarkers is extremely helpful in this pro-cess but does not replace comprehensive clinical assessment.

There are some limitations to this study that are inherent in any systematic review. First, the study has a relatively small selection of studies, and the included studies have tended to be small, limiting the generalization of results. Second, the review is narrative, without sophisticated data analysis methods, without a clear ranking of causality, or an attempt to establish a decision threshold above which "pain biomarkers" can accurately identify the type of pain and its possible cause.

Other biomarkers, such as the use of endogenous neurosteroids as pain biomarkers in psychiatric patients, were also not included in the summary. Although very promising in the absence of randomized review studies, they were not included in this review.

In conclusion, although research into the determination of pain biomarkers is very advanced, it is impossible to diagnose and differentiate pain using these techniques routinely. The history and clinical examination remain invaluable. The search for further research is necessary for the coming years.

In clinical trials, it is possible to distinguish pain biomarkers in mental diseases both at the level of body fluid testing, neuroimaging, and genetic testing, which may, in individual selected cases, facilitate the correct diagnosis and isolate the pathophysiology of pain.

Author Contributions: Conceptualization, P.J.; Writing - Original Draft Preparation, P.J. and U.K.; Writing-Review \& Editing, P.J., U.K., AT, A.G., and M.M. reviewed the literature MM is head Independent Department Laboratory of Molecular Imaging. All authors have read and agreed to the published version of the manuscript. $P J$ is the guarantor of this work.

Funding: This research received no external funding.

Institutional Review Board Statement: Not applicable for studies not involving humans or animals, study did not require ethical approval.

Informed Consent Statement: Not applicable for studies not involving humans.

Conflicts of Interest: The authors declare no conflicts of interest.

\section{References}

1. Velly, A.M.; Mohit, S. Epidemiology of pain and relation to psychiatric disorders. Prog. Neuro Psychopharmacol. Biol. Psychiatry 2018, 87, 159-167, doi:10.1016/j.pnpbp.2017.05.012.

2. Institute of Medicine (US) Committee on Pain, Disability; Chronic Illness Behavior; Osterweis, M.; Kleinman, A.; Mechanic, D. Pain and Disability: Clinical, Behavioral, and Public Policy Perspectives; National Academies Press: Washington, DC, USA, 1987; Volume 9. Available online: https://www.ncbi.nlm.nih.gov/books/NBK219250/ (accessed on 16.Dec 2020).

3. Mansfield, K.E.; Sim, J.; Jordan, J.L.; Jordan, K.P. A systematic review and meta-analysis of the prevalence of chronic widespread pain in the general population. Pain 2016, 157, 55-64, doi:10.1097/j.pain.0000000000000314.

4. Khandelwal, S.K.; Sinha, K. Pain in psychiatric disorders. Indian J. Med. Res. 2017, 146, 142, doi:10.4103/09715916.219023.

5. Fröhlich, D.-P.C.; Jacobi, F.; Wittchen, H.-U. DSM-IV pain disorder in the general population. Eur. Arch. Psychiatry Clin. Neuro-sci. 2005, 256, 187-196, doi:10.1007/s00406-005-0625-3. 
6. Treede, R.-D.; Rief, W.; Barke, A.; Aziz, Q.; Bennett, M.I.; Benoliel, R.; Cohen, M.; Evers, S.; Finnerup, N.B.; First, M.B.; et al. Chronic pain as a symptom or a disease: The IASP Classification of Chronic Pain for the International Classification of Diseases (ICD-11). Pain 2019, 160, 19-27, doi:10.1097/j.pain.0000000000001384.

7. Korwisi, B.; Treede, R.D.; Rief, W.; Barke, A. Evaluation of the International Classification of Diseases-11 chronic pain classifica-tion: Study protocol for an ecological implementation field study in low-, middle-, and high-income countries. Pain Rep. 2020, 5, e825, doi:10.1097/PR9.0000000000000825.

8. Osterweis, M.; Kleinman, A.; Mechanic, D.; Eds. Pain and Disability: Clinical, Behavioral, and Public Policy Perspectives; National

Academies Press (US): Washington, DC, USA, 1987.

9. Peters, M.L. Emotional and cognitive influences on pain experience. Pain Psychiatr. Disord. 2015, 30, 138-152.

10. Tracey, I.; Woolf, C.J.; Andrews, N.A. Composite Pain Biomarker Signatures for Objective Assessment and Effective Treatment. Neuron 2019, 101, 783-800, doi:10.1016/j.neuron.2019.02.019.

11. Boonstra, A.M.; Stewart, R.E.; Köke, A.J.A.; Oosterwijk, R.F.A.; Swaan, J.L.; Schreurs, K.M.G.; Preuper, H.R.S. Cut-Off Points for Mild, Moderate, and Severe Pain on the Numeric Rating Scale for Pain in Patients with Chronic Musculoskeletal Pain: Var-iability and Influence of Sex and Catastrophizing. Front. Psychol. 2016, 7, 1466, doi:10.3389/fpsyg.2016.01466.

12. Crellin, D.J.; Harrison, D.; Santamaria, N.; Huque, H.; Babl, F.E. The Psychometric Properties of the FLACC Scale Used to Assess Procedural Pain. J. Pain 2018, 19, 862-872, doi:10.1016/j.jpain.2018.02.013.

13. Le May, S.; Ballard, A.; Khadra, C.; Gouin, S.; Plint, A.C.; Villeneuve, E.; Mâsse, B.; Tsze, D.S.; Neto, G.; Drendel, A.L.; et al. Comparison of the psychometric properties of 3 pain scales used in the pediatric emergency department: Visual Analogue Scale, Faces Pain Scale-Revised, and Colour Analogue Scale. Pain 2018, 159, 1508-1517, doi:10.1097/j.pain.0000000000001236.

14. Pfeifer, A.-C.; Uddin, R.; Schröder-Pfeifer, P.; Holl, F.; Swoboda, W.; Schiltenwolf, M. Mobile Application-Based Interventions for Chronic Pain Patients: A Systematic Review and Meta-Analysis of Effectiveness. J. Clin. Med. 2020, 9, 3557, doi:10.3390/jcm9113557.

15. Chandrashekar, P. Do mental health mobile apps work: Evidence and recommendations for designing high-efficacy mental health mobile apps. Mhealth 2018, 4, 6, doi:10.21037/mhealth.2018.03.02.

16. Aryana, B.; Brewster, L. Design for mobile mental health: Exploring the informed participation approach. Heal. Inf. J. 2019, 26, 1208-1224, doi:10.1177/1460458219873540.

17. Rathbone, A.L.; Prescott, J. The Use of Mobile Apps and SMS Messaging as Physical and Mental Health Interventions: System-atic Review. J. Med. Int. Res. 2017, 19, e295, doi:10.2196/jmir.7740.

18. Cheng, D.; Liu, D.; Philpotts, L.L.; Turner, D.P.; Houle, T.T.; Chen, L.; Zhang, M.; Yang, J.; Zhang, W.; Deng, H. Current state of science in machine learning methods for automatic infant pain evaluation using facial expression information: Study protocol of a systematic review and meta-analysis. BMJ Open 2019, 9, e030482, doi:10.1136/bmjopen-2019030482.

19. Liu, D.; Cheng, D.; Houle, T.T.; Chen, L.; Zhang, W.; Deng, H. Machine learning methods for automatic pain assessment using facial expression information. Medicine 2018, 97, e13421, doi:10.1097/md.0000000000013421.

20. Wolfe, F.; Clauw, D.J.; Fitzcharles, M.-A.; Goldenberg, D.L.; Häuser, W.; Katz, R.S.; Mease, P.; Russell, A.S.; Russell, I.J.; Winfield, J.B. Fibromyalgia Criteria and Severity Scales for Clinical and Epidemiological Studies: A Modification of the ACR Preliminary Diagnostic Criteria for Fibromyalgia. J. Rheumatol. 2011, 38, 1113-1122, doi:10.3899/jrheum.100594.

21. Rusu, A.-C.; Hasenbring, M. Multidimensional Pain Inventory derived classifications of chronic pain: Evidence for maladaptive pain-related coping within the dysfunctional group. Pain 2008, 134, 80-90, doi:10.1016/j.pain.2007.03.031.

22. Gonzales, V.A.; Martelli, M.F.; Baker, J.M. Psychological assessment of persons with chronic pain. Neuro Rehabil. 2000, 14, 69- 83, PMID: 11455070.

23. Headache Intake Questionnaire. The Cleveland Clinic $\odot$ Copyright and Moral Rights; Brookfield Place: Toronto, ON Canada, 1995- 2009.

24. Attal, N.; Bouhassira, D.; Baron, R. Diagnosis and assessment of neuropathic pain through questionnaires. Lancet Neurol. 2018, 17, 456-466, doi:10.1016/s1474-4422(18)30071-1.

25. Mouraux, A.; lannetti, G.D. The search for pain biomarkers in the human brain. Brain 2018, 141, 3290-3307, doi:10.1093/brain/awy281.

26. Archibald, J.; Warner, F.M.; Ortiz, O.; Todd, M.; Jutzeler, C.R. Recent advances in objectifying pain using neuroimaging tech-niques. J. Neurophysiol. 2018, 120, 387-390, doi:10.1152/jn.00171.2018.

27. Apkarian, A.V.; Bushnell, M.C.; Treede, R.-D.; Zubieta, J.-K. Human brain mechanisms of pain perception and regulation in health and disease. Eur. J. Pain 2005, 9, 463, doi:10.1016/j.ejpain.2004.11.001.

28. Borsook, D.; Moulton, E.A.; Schmidt, K.F.; Becerra, L.R. Neuroimaging Revolutionizes Therapeutic Approaches to Chronic Pain. Mol. Pain 2007, 3, 25, doi:10.1186/1744-8069-3-25.

29. Schweinhardt, P.; Bushnell, M.C. Pain imaging in health and disease-how far have we come? J. Clin. Investig. 2010, 120, 3788- 3797, doi:10.1172/JCl43498.

30. Van Der Miesen, M.M.; Lindquist, M.A.; Wager, T.D. Neuroimaging-based biomarkers for pain: State of the field and current directions. Pain Rep. 2019, 4, e751, doi:10.1097/pr9.0000000000000751. 
31. Marquand, A.; Howard, M.; Brammer, M.; Chu, C.; Coen, S.; Mourão-Miranda, J. Quantitative prediction of subjective pain intensity from whole-brain fMRI data using Gaussian processes. Neurolmage 2010, 49, 2178-2189, doi:10.1016/j.neu-roimage.2009.10.072.

32. Pfannmöller, J.; Lotze, M. Review on biomarkers in the resting-state networks of chronic pain patients. Brain Cogn. 2019, 131, 4- 9, doi:10.1016/j.bandc.2018.06.005.

33. Tinnermann, A.; Büchel, C.; Cohen-Adad, J. Cortico-spinal imaging to study pain. Neurolmage 2021, 224, 117439, doi:10.1016/j.neuroimage.2020.117439.

34. Tatu, K.; Costa, T.; Nani, A.; Diano, M.; Quarta, D.G.; Duca, S.; Apkarian, A.V.; Fox, P.T.; Cauda, F. How do morphological alterations caused by chronic pain distribute across the brain? A meta-analytic co-alteration study. Neuroimage: Clin. 2018, 18, 15-30, doi:10.1016/j.nicl.2017.12.029.

35. Jung, Y.H.; Kim, H.; Jeon, S.Y.; Kwon, J.M.; Kim, Y.C.; Lee, W.J.; Lee, D.; Lee, J.Y.; Moon, J.Y.; Kang, D.H. Neurometabolite changes in patients with complex regional pain syndrome using magnetic resonance spectroscopy: A pilot study. Neuroreport 2019, 30, 108-112.

36. Seminowicz, D.A.; Laferriere, A.L.; Millecamps, M.; Yu, J.S.C.; Coderre, T.J.; Bushnell, M.C. MRI structural brain changes asso-ciated with sensory and emotional function in a rat model of long-term neuropathic pain. Neurolmage 2009, 47, 1007-1014, doi:10.1016/j.neuroimage.2009.05.068.

37. Davis, K.D.; Seminowicz, D.A. Insights for Clinicians from Brain Imaging Studies of Pain. Clin J Pain. 2017, 33, 291294, doi:10.1097/AJP.0000000000000439.

38. Upadhyay, J.; Geber, C.; Hargreaves, R.; Birklein, F.; Borsook, D. A critical evaluation of validity and utility of translational imaging in pain and analgesia: Utilizing functional imaging to enhance the process. Neurosci. Biobehav. Rev. 2018, 84, 407-423.

39. Watson, C.J. Insular balance of glutamatergic and GABAergic signaling modulates pain processing. Pain 2016, 157, 2194-2207, doi:10.1097/j.pain.0000000000000615.

40. Harris, R.E.; Napadow, V.; Huggins, J.P.; Pauer, L.; Kim, J.; Hampson, J.; Sundgren, P.C.; Foerster, B.; Petrou, M.; Schmidt-Wilcke, T.; et al. Pregabalin rectifies aberrant brain chemistry, connectivity, and functional response in chronic pain patients. Anesthesiology 2013, 119, 1453-1464.

41. Martucci, K.T.; Mackey, S.C. Neuroimaging of Pain. Anesthesiology 2018, 128, 1241-1254, doi:10.1097/aln.0000000000002137.

42. Knudsen, L.; Petersen, G.L.; Nørskov, K.N.; Vase, L.; Finnerup, N.; Jensen, T.S.; Svensson, P. Review of neuroimaging studies related to pain modulation. Scand. J. Pain 2011, 2, 108-120, doi:10.1016/j.sjpain.2011.05.005.

43. Maihöfner, C.; Handwerker, H.O.; Neundörfer, B.; Birklein, F. Cortical reorganization during recovery from complex regional pain syndrome. Neurology 2004, 63, 693-701, doi:10.1212/01.wnl.0000134661.46658.b0.

44. Jung, Y.-H.; Kim, H.; Jeon, S.Y.; Kwon, J.M.; Lee, W.J.; Kim, Y.C.; Jang, J.H.; Choi, S.-H.; Lee, J.-Y.; Kang, D.-H. Brain Metabolites and Peripheral Biomarkers Associated with Neuroinflammation in Complex Regional Pain Syndrome Using [11C]-(R)-PK11195 Positron Emission Tomography and Magnetic Resonance Spectroscopy: A Pilot Study. Pain Med. 2018, 20, 504-514, doi:10.1093/pm/pny111.

45. Walton, K.D.; Dubois, M.; Llinás, R.R. Abnormal thalamocortical activity in patients with Complex Regional Pain Syndrome (CRPS) Type I. Pain 2010, 150, 41-51, doi:10.1016/j.pain.2010.02.023.

46. Di Pietro, F.; Lee, B.; Henderson, L.A. Altered resting activity patterns and connectivity in individuals with complex regional pain syndrome. Hum. Brain Mapp. 2020, 41, 3781-3793, doi:10.1002/hbm.25087.

47. Jakubow, P.A.; Garkowski, A.; Kubas, B.; Mojsak, M. Neurometabolite changes in patients with complex regional pain syn-drome using proton magnetic resonance spectroscopy 7th Scientific Conference of PMS. Metab. Circ. 2020, $11,75$.

48. Gram, M.; Graversen, C.; Olesen, A.E.; Drewes, A. Machine learning on encephalographic activity may predict opioid analgesia. Eur. J. Pain 2015, 19, 1552-1561, doi:10.1002/ejp.734.

49. Duff, E.P.; Vennart, W.; Wise, R.G.; Howard, M.A.; Harris, R.E.; Lee, M.; Wartolowska, K.; Wanigasekera, V.; Wilson, F.J.; Whit-lock, M.; et al. Learning to identify CNS drug action and efficacy using multistudy fMRI data. Sci. Transl. Med. 2015, 7, 274ra16, doi:10.1126/scitransImed.3008438.

50. Smith, A.; López-Solà, M.; McMahon, K.; Pedler, A.; Sterling, M. Multivariate pattern analysis utilizing structural or functional MRI-In individuals with musculoskeletal pain and healthy controls: A systematic review. Semin. Arthritis Rheum. 2017, 47, 418-431, doi:10.1016/j.semarthrit.2017.06.005.

51. Reddan, M.C.; Wager, T.D. Modeling Pain Using fMRI: From Regions to Biomarkers. Neurosci. Bull. 2018, 34, 208215, doi:10.1007/s12264-017-0150-1.

52. Koban, L.; Jepma, M.; López-Solà, M.; Wager, T.D. Different brain networks mediate the effects of social and conditioned ex-pectations on pain. Nat. Commun. 2019, 10, 1-13, doi:10.1038/s41467-019-11934-y.

53. Morrison, E.; Sandilands, E.; Webb, D. Gabapentin and pregabalin: Do the benefits outweigh the harms? J. R. Coll. Physicians Edinb. 2017, 47, 310-313, doi:10.4997/jrcpe.2017.402.

54. Jang, E.H.; Park, B.J.; Kim, S.H.; Sohn, J.H. Emotion Classification by Machine Learning Algorithm Using Physiological Signals IPCSIT; IACSIT Press: Singapore, 2012; Volume 25.

55. Krishnan, A.; Woo, C.-W.; Chang, L.J.; Ruzic, L.; Gu, X.; López-Solà, M.; Jackson, P.L.; Pujol, J.; Fan, J.; Wager, T.D. Somatic and vicarious pain are represented by dissociable multivariate brain patterns. Elife 2016, 5, e15166, doi:10.7554/elife.15166. 
56. Rojas, R.F.; Huang, X.; Ou, K.-L. A Machine Learning Approach for the Identification of a Biomarker of Human Pain using fNIRS. Sci. Rep. 2019, 9, 1-12, doi:10.1038/s41598-019-42098-w.

57. Villemure, C.; Slotnick, B.M.; Bushnell, C.M. Effects of odors on pain perception: Deciphering the roles of emotion and attention. Pain 2003, 106, 101-108, doi:10.1016/s0304-3959(03)00297-5.

58. Baliki, M.N.; Apkarian, A.V.; Nociception, Pain, Negative Moods, and Behavior Selection. Neuron 2015, 87, 474-491, doi:10.1016/j.neuron.2015.06.005.

59. Navratilova, E.; Morimura, K.; Xie, J.Y.; Atcherley, C.W.; Ossipov, M.H.; Porreca, F. Positive emotions and brain reward circuits in chronic pain. J. Comp. Neurol. 2016, 524, 1646-1652, doi:10.1002/cne.23968.

60. Villemure, C.; Bushnell, M.C. Mood Influences Supraspinal Pain Processing Separately from Attention. J. Neurosci. 2009, 29, 705-715, doi:10.1523/jneurosci.3822-08.2009.

61. Berna, C.; Leknes, S.; Holmes, E.A.; Edwards, R.R.; Goodwin, G.M.; Tracey, I. Induction of Depressed Mood Disrupts Emotion Regulation Neurocircuitry and Enhances Pain Unpleasantness. Biol. Psychiatry 2010, 67, 1083-1090, doi:10.1016/j.bi-opsych.2010.01.014.

62. Villemure, C.; Bushnell, C.M. Cognitive modulation of pain: How do attention and emotion influence pain processing? Pain 2002, 95, 195-199, doi:10.1016/s0304-3959(02)00007-6.

63. Corbetta, M.; Shulman, G.L. Control of goal-directed and stimulus-driven attention in the brain. Nat. Rev. Neurosci. 2002, 3, 201- 215, doi:10.1038/nrn755.

64. Marinus, J.; Moseley, G.L.; Birklein, F.; Baron, R.; Maihöfner, C.; Kingery, W.S.; van Hilten, J.J. Clinical features and pathophys-iology of complex regional pain syndrome. Lancet Neurol. 2011, 10, 637-648, doi:10.1016/s14744422(11)70106-5.

65. Clark, J.D.; Tawfik, V.L.; Tajerian, M.; Kingery, W.S. Autoinflammatory and autoimmune contributions to complex regional pain syndrome. Mol. Pain 2018, 14, doi:10.1177/1744806918799127.

66. Kong J, Jensen K, Loiotile R, et al. Functional connectivity of the frontoparietal network predicts cognitive modulation of pain. Pain. 2013;154(3):459-467. doi:10.1016/j.pain.2012.12.004

67. Bäckryd, E. Pain in the Blood? Envisioning Mechanism-Based Diagnoses and Biomarkers in Clinical Pain Medicine. Diagnostics 2015, 5, 84-95, doi:10.3390/diagnostics5010084.

68. Niculescu, A.B.; Le-Niculescu, H.; Levey, D.F.; Roseberry, K.; Soe, K.C.; Rogers, J.; Khan, F.; Jones, T.; Judd, S.; McCormick, M.A.; et al. Towards precision medicine for pain: Diagnostic biomarkers and repurposed drugs. Mol. Psychiatry 2019, 24, 501- 522, doi:10.1038/s41380-018-0345-5.

69. Konikowska, K.; Regulska-Ilow, B.; Rózańska, D. The influence of components of diet on the symptoms of ADHD in children.

Rocz. Państwowego Zakładu Hig. 2012, 63, 22928358.

70. Marazziti, D.; Mungai, F.; Vivarelli, L.; Presta, S.; Dell'Osso, B. Pain and psychiatry: A critical analysis and pharmacological review. Clin. Pr. Epidemiol. Ment. Heal. 2006, 2, 31, doi:10.1186/1745-0179-2-31.

71. Diniz, B.S.; Mendes-Silva, A.P.; Silva, L.B.; Bertola, L.; Vieira, M.C.; Ferreira, J.D.; Nicolau, M.; Bristot, G.; Da Rosa, E.D.; Teixeira, A.L.; et al. Oxidative stress markers imbalance in late-life depression. J. Psychiatr. Res. 2018, 102, 2933, doi:10.1016/j.jpsychires.2018.02.023.

72. Peabody, J.; Paculdo, D.; Tamondong-Lachica, D.; Cabaluna, I.T.; Gunn, J. Randomized Trial on the Clinical Utility of a Novel Biomarker Panel to Identify Treatable Determinants of Chronic Pain. Diagnostics 2020, 10, 513, doi:10.3390/diagnostics10080513.

73. Amirdelfan, K.; Pope, J.E.; Gunn, J.; Hill, M.M.; Cotten, B.M.; Beresh, J.E.; Dobecki, D.; Miller, N.; Mehta, P.; Girardi, G.; et al. Clinical Validation of a Multi-Biomarker Assay for the Evaluation of Chronic Pain Patients in a Cross-Sectional, Observational Study. Pain 2020, 9, 511-529, doi:10.1007/s40122-020-00175-3.

74. Brena, S.F.; US Department of Health and Human Services; National Institute on Drug Abuse; Chapman, S.L.; Decker, R. Chronic Pain as a Learned Experience: Emory University Pain Control Center. Psycextra Dataset 1981, doi:10.1037/e497142006-007.

75. Gunn, J.; Hill, M.M.; Cotten, B.M.; Deer, T.R. An Analysis of Biomarkers in Patients with Chronic Pain. Pain Physician 2020, 23, E41-E49.

76. Autié A, Montreuil M, Moulier V, Braha S, Wojakiewicz A, Januel D. Douleur et schizophrénie: mythe et réalité [Pain and schizophrenia: myth and reality]. Encephale. 2009 Sep;35(4):297-303. French. doi: 10.1016/j.encep.2008.04.005. Epub 2008 Oct 23. PMID: 19748365.

77. Li D, Song X, Huang H, Huang H, Ye Z. Association of Parkinson's disease-related pain with plasma interleukin-1, interleukin-6, interleukin-10, and tumour necrosis factor-a. Neurosci Lett. 2018 Sep 14;683:181-184. doi: 10.1016/j.neulet.2018.07.027. Epub 2018 Jul 29. PMID: 30063943.

78. Cao S, Fisher DW, Yu T, Dong H. The link between chronic pain and Alzheimer's disease. J Neuroinflammation. 2019 Nov 6;16(1):204. doi: 10.1186/s12974-019-1608-z. PMID: 31694670; PMCID: PMC6836339. 
79. Cantón-Habas V, Carrera-González MDP, Moreno-Casbas MT, et al Correlation between biomarkers of pain in saliva and PAINAD scale in elderly people with cognitive impairment and inability to communicate: descriptive study protocol BMJ Open 2019;9:e032927. doi: 10.1136/bmjopen-2019-032927

80. Naylor JC, Kilts JD, Szabo ST, Dunn CE, Keefe FJ, Tupler LA, Shampine LJ, Morey RA, Strauss JL, Hamer RM, Wagner HR; MIRECC Workgroup, Marx CE. Allopregnanolone Levels Are Inversely Associated with Self-Reported Pain Symptoms in U.S. Iraq and Afghanistan-Era Veterans: Implications for Biomarkers and Therapeutics. Pain Med. 2016 Jan;17(1):25-32. doi: 10.1111/pme.12860. PMID: 26176345.

81. Rustichelli C, Bellei E, Bergamini S, et al. Comparison of pregnenolone sulfate, pregnanolone and estradiol levels between patients with menstrually-related migraine and controls: an exploratory study. J Headache Pain. 2021;22(1):13. Published 2021 Mar 23. doi:10.1186/s10194-021-01231-9

82. Mason BL, Van Enkevort E, Filbey F, Marx CE, Park J, Nakamura A, Sunderajan P, Brown ES. Neurosteroid Levels in Patients With Bipolar Disorder and a History of Cannabis Use Disorders. J Clin Psychopharmacol. 2017 Dec;37(6):684-688. doi: 10.1097/JCP.0000000000000793. PMID:

83. Almeida FB, Barros HMT, Pinna G. Neurosteroids and Neurotrophic Factors: What Is Their Promise as Biomarkers for Major Depression and PTSD? Int J Mol Sci. 2021 Feb 10;22(4):1758. doi: 10.3390/ijms22041758. PMID: 33578758; PMCID: PMC7916492. 